16 Kotelko DM. Shnider SM, Dailey PA et al. Bupivacaine induced cardiac arrhythmias in sheep. Anesthesiology, 1984; 60: 10-8.

17 Albright GA. Epinephrine should be used with the therapeutic dose of bupivacaine in obstetrics. Anesthesiology $1984 ; 61: 217-8$.

\section{Factors influencing the presence of a leak around an endotracheal tube in patients with croup}

\section{To the Editor:}

The consequences of inappropriate extubation are very serious. We wish, therefore to comment on the survey by Drs. Adderley and Mullins,' in which the reliability of the "leak test" as a criterion for elective extubation of children with croup was assessed.

The factors influencing the occurrence of a "leak" around a tracheal tube, previously stated by Finholt $e t$ $a l .,^{2}$ are repeated by the authors. They include the amount of positive pressure applied to the tube, the presence of airway narrowing below the tube, the presence of neuromuscular blockade, and head position. However, Finholt et al. studied patients requiring tracheal intubation for elective surgical procedures and used the "leak" test to assess tracheal tube fit. They state quite clearly that the test is invalidated if complete muscle paralysis was not present.

We suggest that the factor of overriding importance in determining the presence of an audible leak around a tracheal tube in a patient with croup is the size of the tube in relation to the normal tracheal diameter. If, for example, a 24-month-old child, who would normally be intubated with a tracheal tube of internal diameter of $4.5-5.0 \mathrm{~mm}$ is intubated with a $3.0 \mathrm{~mm}$ tube during an episode of croup, any leak which subsequently occurs will occur at an earlier stage in the recovery process than if the same child had been intubated with a $3.5 \mathrm{~mm}$ tube.

The size of the tracheal tube in relation to the normal tracheal diameter must be a factor of major importance in determining when a leak occurs during the recovery phase of a child with croup. Account must be taken of this when the "leak test" is used to assess the timing of elective cxtubation. On its own, the test cannot be an adequate predictor of the patient's ability to manage without a tracheal tube. The consequences of premature extubation are so serious that we recommend that extubation be performed under inhalational anaesthesia, with facilities for immediate reintubation.

\author{
A.M. Severn MB FFARCS \\ P.M. Spargo MrCP FFaRCS \\ Department of Anaesthetics \\ Queen Alexandra Hospital \\ Cosham \\ Portsmouth P06 3LY \\ United Kingdom
}

\section{REFERENCES}

1 Adderley RJ, Mullins GC. When to extubate the croup patient: the "leak" test. Can J Anaesth 1987; 34: 304-6.

2 Finholt DA, Henry DB, Raphaely RC. The "leak test" - a standard method for assessing tracheal tube fit in pediatric patients. Aneschesiology 1984; 61: A450.

\section{$R E P L Y$}

We have defined our "leak" which we believe is useful for predicting when to extubate a patient with croup, and this is not to be confused with Finholt's "leak" which is defined differently and serves a different purpose, i.e., elecitve surgical procudures in paliants without inflammatory disease of the upper airway. We did refer to Finholt's paper in the discussion but emphasized that their set of criteria, including full paralysis with neuromuscular agents, was really not applicable in the decision to extubate the child with croup

We have no argument that the ube size used in intubaling a child with croup is very important, particularly the dangers encountered with using a tube which might be too large; however, we feel that the tube sizes indicated in Table I of the article in general are appropriate for children with croup.

We cannot agree with the recommendation to extubale under inthalational anaesthesia as a routine. Certainly extubation under anaesthesia is appropriate if extubation is being attempted in the absence of a "leak" and certainly there should be facilities available for invnediate re-intubation wherever extubation takes place. These children should be watrhed rarefully in an intensive care setting for at least 24 hours following extubation. However. if extubation is going to fail. the obstruction generally gradually and progressively gets worse over hours. In one of the eight patients in the series who failed exiubation, re-intubation was required at greater than 24 hours.

Therefore successfil extubation under anaesthesia in the Operating Room is not an adequate predictor of a patient's ability to manage without a tracheal tube.

\section{Robert J. Adderley MD FRCPC}

Intensive Care Unit

British Columbia's Children's Hospital

4480 Oak Street

Vancouver, British Columbia

V6H $3 \mathrm{VH}$ 